\title{
Influence of Multiple \& Cooperative Hydrogen Bonding on the Acidity of Polyhydroxylated Piperidines: Electron Density Topological Analysis
}

Marjan Jebeli Javan ( $\nabla$ m.jebelijavan@iautmu.ac.ir)

Islamic Azad University Tehran Medical Sciences https://orcid.org/0000-0002-4589-0647

\section{Research Article}

Keywords: polyhydroxylated piperidines, hydrogen bonding, gas-phase acidity, pKa, dimethyl sulfoxide

Posted Date: July 1st, 2021

DOl: https://doi.org/10.21203/rs.3.rs-653218/v1

License: (c) (1) This work is licensed under a Creative Commons Attribution 4.0 International License.

Read Full License

Version of Record: A version of this preprint was published at Structural Chemistry on August 30th, 2021. See the published version at https://doi.org/10.1007/s11224-021-01821-y. 


\title{
Influence of Multiple \& Cooperative Hydrogen Bonding on the Acidity of Polyhydroxylated Piperidines: Electron Density Topological Analysis
}

\author{
Marjan Jebeli Javan* \\ Department of Organic Chemistry, Faculty of Pharmaceutical Chemistry, Tehran Medical Sciences, \\ Islamic Azad University, Tehran, Iran, ORCID ID: 0000-0002-4589-0647 \\ *Corresponding author: m.jebelijavan@iautmu.ac.ir
}

\begin{abstract}
Abstarct
Hydrogen bonds are the presiding concepts for arranging the three-dimensional forms of biological molecules like proteins, carbohydrates and nucleic acids, and acts as guides for proton transfer reactions. Gas-phase acidity and $\mathrm{p} K_{\mathrm{a}}$ calculations in dimethyl sulfoxide on a line of polyhydroxylated piperidines specify that multiple hydrogen bonds lead to enhance acidities.

The gas-phase acidity (GPA) of polyhydroxylated piperidines was investigated by MP2/6$311++\mathrm{G}(\mathrm{d}, \mathrm{p}) / / \mathrm{B} 3 \mathrm{LYP} / 6-311++\mathrm{G}(\mathrm{d}, \mathrm{p})$ method. For each structure, varied primary and secondary hydroxyl groups were deprotonated. The natural bond orbital (NBO) and quantum theory of atoms in molecules (QTAIM) analyses have also been used to realize the character of the hydrogen bonding interactions in these compounds.

The results show by adding each hydroxyl group, $\Delta \mathrm{H}_{\text {acid }}$ in the gas phase (it becomes less endothermic) and $\mathrm{p} K_{\mathrm{a}}$ value in the solution phase was decreased. Therefore, intramolecular hydrogen bonds lead to enhance the acid strength. In both the gas phase and solution phase, the $\beta$-Nojrimycin-OH2 ( $\beta$-1-OH2) was found to be the most acidic compound with calculated gas-phase acidity (GPA) of $349.4 \mathrm{kcal}^{\mathrm{mol}}{ }^{-1}$ and the $\mathrm{p} K_{\mathrm{a}}$ value of $22.0\left(8.0 \mathrm{p} K_{\mathrm{a}}\right.$ units more acidic than 1-propanol).

It was also shown, applying the polarized continuum model ( $\mathrm{PCM})$, there is a superior linear correlation with the gas phase acidities (GPAs) of polyhydroxylated piperidines and their calculated $\mathrm{p} K_{\mathrm{a}}$ (DMSO) values.
\end{abstract}

Keywords: polyhydroxylated piperidines, hydrogen bonding, gas-phase acidity, $\mathrm{p} K_{\mathrm{a}}$, dimethyl sulfoxide 


\section{Introduction}

The systemic analogs of sugars in which the ring oxygen atom is substituted by a nitrogen atom are iminosugars. Recently, there has been much attraction in naturally occurring and synthetic iminosugars. Since iminosugars interfere with the function of carbohydrate processing enzymes, their biological effects emerge [1]. Naturally occurring sugars with a nitrogen atom in the ring are allocated into five structural categories: pyrrolidines, indolizidines, polyhydroxylated piperidines, pyrrolizidines, and nortopanes [2]. Nowadays, polyhydroxylated piperidines ("azasugars") have acquired considerable attention. These alkaloidal sugar mimics involve the matching stereochemical details as the usual hexoses, and lots of them reveal powerful biotic activity [2]. The region of biological attraction reclines in oligosaccharide-processing enzyme inhibition called glycosyl transferases and glycosidases. By sustaining an intermediate oxonium ion, these enzymes perform upon the glycosidic linkage of glycopeptides and oligosaccharides, therefore accelerate the alteration and lysis of the anomeric center [3-6]. The O/N acetal basis of aza- $O$-glycosides is labile in hydrolytic situations, thus restricting the expansion of this group of glycomimetics [7, 8]. The existence of an anomeric group, especially one that favors a second sugar unit, may supply greater power and/or more selectivity in identification by an aimed enzyme.

Also, azasugars have been presumed as feasible therapeutics involving the therapy of viral diseases, diabetes, and cancers, and as crucial tools in the enzyme mechanism researches [9]. These polyhydroxylated piperidines generally named iminosugars ('azasugars'), intimately favor monosaccharides in respect to their structure and shape. The first endocyclic nitrogen analog of glucose discovered in 1966, was Nojrimycin 1. Nojrimycin, was exhibited as a dominant inhibitor of $\alpha$ and $\beta$-glucosidases which was first excluded from various stains of Streptomyces, Bacillus, and mulberry tree leaves as an antibiotic [10,11]. Reduction of nojrimycin results in 1-deoxynojrimucin 2, a longer-lasting compound, as a glucosidase inhibitor [12,13]. Isofagomine 3, another example of iminosugars is around 440 times more powerful than 1-deoxynojrimycin 2 toward $\beta$-glucosidases but is only a medium $\alpha$-glucosidases inhibitor [13, 14]. Likewise, (C)-galactonojirimycin 4 and its reduction product (C)-1-deoxygalactonojirimycin 5 exhibit strong inhibitory activity approaching several $\beta$-galactosidases $[15,16]$ and $\alpha$-galactosidases $[17,18]$. 1deoxygulonojirimycin $\boldsymbol{6}$ is a vigorous and selective inhibitor of fucosidases [19, 20] (Fig 1).

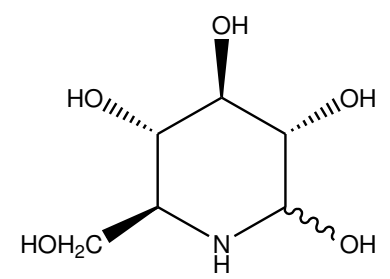

1

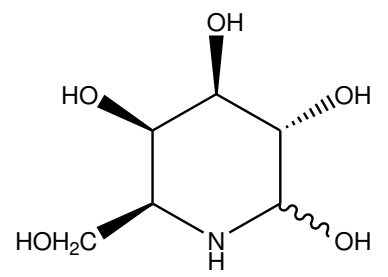

4
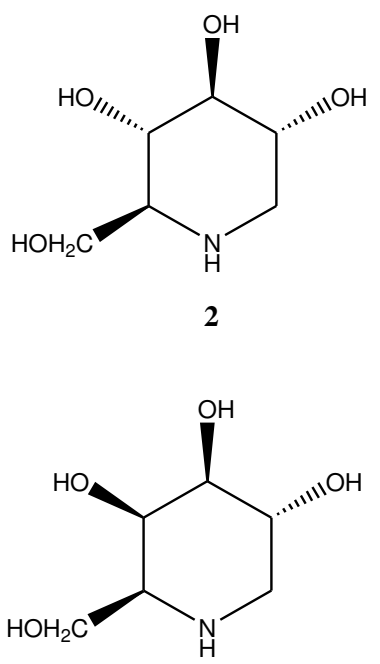

5
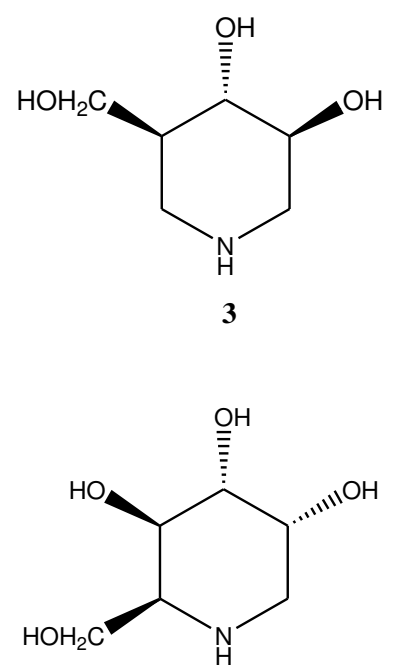

6 
Fig. 1 Glycosidase inhibitors with the 1-deoxy-azasugars structure

In the practical and theoretical opinion, the fascinating behavior of intramolecular hydrogen bonds has received blooming attention recently [21-29]. Since the hydrogen bond energy value is only a few $\mathrm{kcal} / \mathrm{mol}$ and can be disturbed by any change in its surroundings. In studies of larger scale bio-molecules and feeble bound complexes, this is important. Because hydrogen bonding interactions are commonly more fragile than traditional chemical bonds, they play an important role in chemical and physical properties in both intramolecular and intermolecular interactions. Lots of important characteristics, containing aqueous solubility, viscosity and lipophilicity, boiling, and melting points, are directly related to the scope of organic molecules to form hydrogen bonds which affect very notably a wide array of their physical properties [27]. Moreover, in a crowd of chemical transformations, acid-base reactions are universal and play a censorious role. Hydrogen bonds arrange three-dimensional forms of O-H and N-H containing compounds, serve as pathfinders for proton transfer reactions, and also decrease the gas-phase deprotonation enthalpies of alcohols [30]. For Instance ethylene glycol $\left(\mathrm{HOCH}_{2} \mathrm{CH}_{2} \mathrm{OH}\right)$ is $13.6 \pm 2.6 \mathrm{kcal} / \mathrm{mol}\left(10 \pm 2 \mathrm{p} K_{\mathrm{a}}\right.$ units $)$ more acidic than ethanol $\left(\mathrm{CH}_{3} \mathrm{CH}_{2} \mathrm{OH}\right)$, and 1,3-propanediol $\left(\mathrm{HOCH}_{2} \mathrm{CH}_{2} \mathrm{CH}_{2} \mathrm{OH}\right)$ is more acidic than 1-propanol $\left(\mathrm{CH}_{3} \mathrm{CH}_{2}-\mathrm{CH}_{2} \mathrm{OH}\right)$ by 17.7 $\pm 2.8 \mathrm{kcal} / \mathrm{mol}\left(13 \pm 2 \mathrm{p} K_{\mathrm{a}}\right.$ units $)$ [31, 32]. Substituent effects in the gas phase are useful to comprehend how the replacement of atoms or groups in a molecule may influence their local and global reactivity motifs [33]. Chemical exchange may be observed as worldwide changes in lots of electrons that obtain both local and global responses at the active site [34-36]. In the early 1970s, Brauman et al. exhibited that $\alpha$-methyl substitution affects the acidity of alcohols as following: $\mathrm{CH}_{3} \mathrm{OH}>\mathrm{CH}_{3} \mathrm{CH}_{2} \mathrm{OH}>\left(\mathrm{CH}_{3}\right)_{2} \mathrm{CHOH}>\left(\mathrm{CH}_{3}\right)_{3} \mathrm{COH}$ [37].

The gas-phase acidity and $\mathrm{p} K_{\mathrm{a}}$ of a chain of polyols in dimethyl sulfoxide were measured [38] and the results show that multiple hydrogen bonds to a single charged center caused considerably increased acidities (SHEA acids). According to these results, we performed a systematic computational study by employing MP2/6$311++\mathrm{G}(\mathrm{d}, \mathrm{p}) / / \mathrm{B} 3 \mathrm{LYP} / 6-311++\mathrm{G}(\mathrm{d}, \mathrm{p})$ method to investigate the effect of multiple hydrogen bonds on acidity enhancement of polyhydroxylated piperidines as cyclic polyols. Using DFT methods have allocated an economical tool for procuring correct thermochemical data and this paper presents the results derived for polyhydroxylated piperidines. The goal of the current work is to establish a relation between calculated $\mathrm{p} K_{\mathrm{a}}$ values in DMSO and theoretical gas-phase acidity (GPA) for a series of polyhydroxylated piperidines. Afterward, this linear relationship will be used to predict the acidity of some new similar acids in this main solvent.

\section{Computational Methods}

Structured conformational search as applied in Spartan software was carried out using the MMFF level [39]. Optimization of the lowest energy structures (those in $10 \mathrm{kcal} / \mathrm{mol}$ of the most approving conformer) used by density functional theory (DFT) calculations with a nonlocal hybrid B3LYP (Becke-Lee-Parr) exchange-correlation functional $[40,41]$ and the $6-311++\mathrm{G}(\mathrm{d}, \mathrm{p})$ atomic basis set. This specific hybrid function has been proved suitable for the study of inter- and intramolecular hydrogen bonds. Energy minimizations subsequently harmonical vibrational computations were carried out at this level of theory. The non-appearance of imaginary frequencies demonstrated that energy-minimized conformers correlate to the local minima of the energy environment. 
The gas phase acidity of a specified compound HA may be explained as the Gibbs energy change $\Delta \mathrm{G}_{\text {acid }}$ (A) for the next deprotonation reaction, $\mathrm{HA}(\mathrm{g}) \rightarrow \mathrm{H}^{+}(\mathrm{g})+\mathrm{A}^{-}(\mathrm{g})$ where $\mathrm{HA}$ and $\mathrm{A}^{-}$elucidate free molecules and their deprotonated structures. Due to the following link, the $\Delta \mathrm{G}_{\text {acid }}$ value was evaluated:

$$
\begin{gathered}
\Delta \mathrm{H}_{\mathrm{acid}}(\mathrm{HA})=\mathrm{E}\left(\mathrm{A}^{-}\right)+\mathrm{E}\left(\mathrm{H}^{+}\right)-\mathrm{E}(\mathrm{HA})+\Delta(\mathrm{PV}) \\
=\mathrm{E}\left(\mathrm{A}^{-}\right)-\mathrm{E}(\mathrm{HA})+(5 / 2) \mathrm{RT} \\
\Delta \mathrm{G}_{\mathrm{acid}}=\Delta \mathrm{H}_{\text {acid }}-\mathrm{T} \Delta \mathrm{S} \quad\left(\Delta \mathrm{S}=\mathrm{S}(\mathrm{HA})-\mathrm{S}\left(\mathrm{A}^{-}\right)-\mathrm{S}\left(\mathrm{H}^{+}\right)\right)
\end{gathered}
$$

where, E is the intended total energy at $298 \mathrm{~K}$. The (5/2)RT phrase contains the proton translation energy. The entropy of the species is defined as $\mathrm{S}$ character (For the $\mathrm{H}^{+}$product, $\mathrm{S}_{298}=109.047 \mathrm{~J} \mathrm{~mol}^{-1} \mathrm{~K}^{-1}$ ) [42]. The term $\Delta \mathrm{G}_{\text {acid }}$ is denoted by GPA (Gas Phase Acidity) in this study. Since $\mathrm{A}^{-}(\mathrm{g})$ and $\mathrm{H}^{+}(\mathrm{g})$ are not solvated in gas phase, the larger value of GPA leads to the frail HA acidity (i.e., deprotonation of HA becomes more endothermic).

The solvation effect was considered by Polarized Continuum Model [43]. In order to decrease the computational charge, every computation in the solution was done with the gas-phase optimized geometries. Calculating the total change in free energy for the solution-phase deprotonation reaction is a simple way to estimate $\mathrm{p} K_{\mathrm{a}}$ :

$$
\mathrm{HA}_{(\text {solv })} \rightarrow \mathrm{H}_{(\text {solv })}^{+}+\mathrm{A}_{\text {(solv) }}^{-}
$$

Where "solv" designates the suitable solvation conditions. Because the chemical structure of solvated proton is usually unclear and difficult to model theoretically, problems appear when treating the solvated proton. Proton has powerful interactions with the adjacent solvent molecules and is much smaller than other cations in acid-base reactions. Considering a testimonial deprotonation reaction whose $\mathrm{p} K_{\mathrm{a}}$ is known experimentally is the attitude used in this paper.

$$
\mathrm{HB}{ }_{(\text {solv })} \rightarrow \mathrm{H}^{+}{ }_{(\text {solv })}+\mathrm{B}_{(\text {solv })}
$$

The following common acid-base reaction by combining equations 1 and 2 can be considered because free energy is a state function:

$$
\mathrm{HA}_{(\text {solv })}+\mathrm{B}_{(\text {solv) }}^{-} \rightarrow \mathrm{HB}_{(\text {solv })}+\mathrm{A}_{(\text {(solv) }}^{-}
$$

The Gibbs free energy of equation 2 (signified by $\Delta G_{2}$ ) for the announcer acid HB can be obtained from its experimental $\mathrm{p} K_{\mathrm{a}}$ content, $\Delta G_{2}=(2.303 \mathrm{RT}) \mathrm{p} K_{\mathrm{a}}(\mathrm{HB})$; while the free energy of equation 3 (signified by $\left.\Delta G_{3}\right)$ can be found from a theoretical estimation. The $\mathrm{p} K_{\mathrm{a}}$ of the unrevealed acid HA in equation 1 can be taken out from the free energy of eqs 2 and 3 as:

$$
\mathrm{p} K_{\mathrm{a}}(\mathrm{HA})=\frac{\Delta \mathrm{G}_{2}+\Delta \mathrm{G}_{3}}{2.303 \mathrm{RT}}=\mathrm{p} K_{\mathrm{a}}(\mathrm{HB})+\frac{\Delta \mathrm{G}_{3}}{2.303 \mathrm{RT}}
$$

The $\mathrm{p} K_{\mathrm{a}}$ values of all species examined here are calculated using PCM/MP2/6-31+G(d)//B3LYP/6-31+G(d) model. 
Natural bond orbital (NBO) analysis was accomplished by the B3LYP functional and the 6-311++G (d,p) basis set. Hyperconjugation is a balancing effect that emerges from an overlap between an occupied orbital with adjunct neighboring electron deficient orbital when these orbitals are accurately aligned. The hyperconjugative interactions has been investigated in these conditions. This non-covalent bonding-antibonding interchange can be numerically reported concerning the NBO method that is indicated employing the second-order perturbation interaction energy $\left(E^{2}\right)$ [44-48]. The approximate of the off-diagonal NBO Fock matrix elements constitute this energy. It can be extrapolated from the second-order perturbation procedure:

$$
E^{2}=\Delta E_{i j}=q_{i} \frac{F(i, j)^{2}}{\varepsilon_{j}-\varepsilon_{i}}
$$

where, $\mathrm{F}(\mathrm{i}, \mathrm{j})$ is the off-diagonal NBO Fock matrix part, $\mathrm{q}_{\mathrm{i}}$ is the donor orbital occupation, and $\varepsilon_{\mathrm{i}} ; \varepsilon_{\mathrm{j}}$ are diagonal parts (orbital energies).

In general, the H-bond formation can be approximated by the structural frameworks (e.g., hydrogen bond angle and length). By shortening or enlarging the H-bond length, the strength of this bond can also be found out. However, the structural variables cannot supply adequate data to correctly express the character of hydrogen bonding interactions in the biotic system. Thus, a well-organized method describing hydrogen bonding interactions is extremely sensible. The natural bond orbital (NBO) and quantum theory of atoms in molecules (QTAIM) analysis have demonstrated to be suitable functional instruments in representing electron densities in numerous systems and understanding H-bond character[49-51]. Based on QTAIM, the electron density $\rho(r)$ at BCP point is correlated with the bond order or bond strength and the presence of a bond critical point (BCP) between two atoms is a general measure of bonded interactions. Thus, to study the nature of $\mathrm{H}$-bond, the presence of $\mathrm{BCP}$ and the topological properties of electron density $\rho(r)$ can be used. Mainly, based on QTAIM, a set of criteria for the existence of H-bonds were proposed [52]. The standards prepare a foundation to differentiate these interactions from van der Waals and have been manifested to be rational for typical and untraditional H-bonds.

The common standards of the hydrogen bonding existence are the Laplacian of the electron density $\nabla^{2} \rho(r)$ at the BCPs and the electron density $\rho(r)$. Laplacian of $\rho(r)$ is connected with the bond interaction energy by a district declaration of the viral formula:

$$
\left(\frac{\hbar^{2}}{4 m}\right) \nabla^{2} \rho(r)=2 G(r)+V(r)
$$

Where, $V(r)$ is the electronic potential energy density and $G(r)$ is the electronic kinetic energy density [49]. ${ }^{51}$ The extra potential energy at BCP revealed by a negative $\nabla^{2} \rho(r)$. This signifies that electronic charge is centered in the inter-nuclear area, and consequently, divided by two nuclei. This occurs for every shared electron (covalent) interconnection. A positive $\nabla^{2} \rho(r)$, at a BCP discloses that the kinetic energy donation is larger than that of potential energy, and exhibits a reduction of electronic charge on the bond path. This happens for every closed-shell electrostatic 
interaction [53]. ${ }^{52}$ The $H(r)$ sign determines even if the accretion of charge at a specified point $r$ is destabilizing $(H(r)$ $>0)$ or stabilizing $(H(r)<0)$. Using the following equation, the hydrogen bonds energies $\left(\mathrm{E}_{\mathrm{H} \ldots \mathrm{x}}\right)$ were computed:

$$
\mathrm{E}_{\mathrm{H} \ldots \mathrm{x}}=1 / 2 \mathrm{~V}(\mathrm{r})
$$

In this study, the electron density topological effects of structures were calculated by the AIM2000 program [54].

\section{Results and discussion}

\subsection{Nomenclature}

In order to discuss the conformational properties of polyhydroxylated thiopyrans, it is essential to recruit a steno script that describes all the ring hydroxyl rotamers. A nomenclature protocol to express several conformer structures of D-glucose in their theoretical analysis of glucose conformations in aqueous media was set up by Cramer and Truhlar [55]. To report conformers of deprotonated $\alpha$-D-glucose, Mulroney et al. administered an adjusted form of the CramerTruhlar terminology with inclusion rules [56]. The hydroxymethyl $\left(\mathrm{CH}_{2} \mathrm{OH}\right)$ conformation is explained using the capital letters $\mathrm{G}^{-}, \mathrm{G}$ and $\mathrm{T}$, and the hydroxyl conformations by the letters $\mathrm{g}^{-}$, $\mathrm{g}$ and $\mathrm{t}$ (see Fig. 2 for more details). For the hydroxyl hydrogen's on $\mathrm{C}(1), \mathrm{C}(2), \mathrm{C}(3)$, and $\mathrm{C}(4)$ of the polyhydroxylated piperidines ring, the letter $\mathrm{g}^{-}$[gauche $(-)], \mathrm{t}[$ trans $]$, and $\mathrm{g}$ [gauche (+)] were continued in the Mulroney-Peel-Traeger nomenclature to designate the H-O$\mathrm{C}(\mathrm{n})-\mathrm{C}(\mathrm{n}-1)$ dihedral angle (or the $\mathrm{O}(6)-\mathrm{C}(6)-\mathrm{C}(5)-\mathrm{N}(5)$ dihedral for $\left.\mathrm{CH}_{2} \mathrm{OH}\right)$. In current work, gauche (-) conveys that a counterclockwise (viewed in the N-to-C(n) order) rotation of the $\mathrm{OH} \leq 120^{\circ}$ is essential to eclipse the bond $\mathrm{C}(\mathrm{n})-\mathrm{C}(\mathrm{n}-1)$, whereas for gauche $(+)$ the orientation is clockwise. For the dihedral angles $>120^{\circ}$, the trans orientation has been allocated. Eventually, the letter $x$ denotes the deprotonated site. It's worth mentioning that all H...O distances near $2.5 \AA$ were assorted as feasible hydrogen bonds.

\subsection{Relative gas-phase acidities (GPAs) of piperidine-n-ols}

As mentioned, this study concentrates on the impact of hydrogen bonding on the acidity of polyhydroxylated piperidines. To investigate the collaborative intramolecular hydrogen bonding schemes inside distinct structures, we first investigated the GPAs of piperidine-n-ols $(n=1,2,3,6)$. The total and relative energies of the numerous structures inspected for the piperidine-n-ols summarized in Table 1. The resulting absolute GPAs are also shown in this Table.

Table 1 Total energies (hartree), relative energies $\left(\mathrm{kcal} . \mathrm{mol}^{-1}\right), \Delta \mathrm{H}_{\text {acid }}\left(\mathrm{kcal}^{\mathrm{mol}}{ }^{-1}\right)$ and GPA $\left(\mathrm{kcal}^{\mathrm{mol}} \mathrm{l}^{-1}\right)$ of different structures of piperidine-n-ols.

\begin{tabular}{lllllll}
\hline \multirow{2}{*}{ piperidine-n-ols } & \multicolumn{2}{l}{ OH conformation } & & & & \\
\cline { 2 - 3 } & Neural & Anion & & & $\Delta \mathrm{H}_{\text {acid }}$ & GPA \\
\hline
\end{tabular}




\begin{tabular}{rllllll}
\hline piperidine-1-ol $(a)$ & $\mathrm{g}$ & $\mathrm{x}$ & -324.5145 & 1.5 & 384.7 & 377.3 \\
$(e)$ & $\mathrm{g}$ & $\mathrm{x}$ & -324.5168 & 0.0 & 383.8 & 376.1 \\
piperidine-2-ol $(a)$ & $\mathrm{g}^{-}$ & $\mathrm{x}$ & -324.5134 & 0.0 & 381.2 & 374.0 \\
$(e)$ & $\mathrm{g}$ & $\mathrm{x}$ & -324.5110 & 1.5 & 382.2 & 374.9 \\
piperidine-3-ol $(a)$ & $\mathrm{g}$ & $\mathrm{x}$ & -324.5099 & 0.1 & 381.2 & 373.9 \\
$(e)$ & $\mathrm{t}$ & $\mathrm{x}$ & -324.5101 & 0.0 & 383.3 & 375.9 \\
piperidine-6-ol $(a)$ & $\mathrm{g}$ & $\mathrm{x}$ & -363.5527 & 1.0 & 381.7 & 375.7 \\
$(e)$ & $\mathrm{g}$ & $\mathrm{x}$ & -363.5542 & 0.0 & 382.7 & 375.8 \\
\hline
\end{tabular}

As shown in Table 1, for axial conformers, the $\mathrm{OH}(3)$ is the most acidic and the following order of acidity was achieved: $\mathrm{OH}(3)>\mathrm{OH}(2)>\mathrm{OH}(6)>\mathrm{OH}(1)$. Moreover, for equatorial conformers, the next sequence of acidity was: $\mathrm{OH}(2)>\mathrm{OH}(6)>\mathrm{OH}(3)>\mathrm{OH}(1)$. The most stable structure for each anion of piperidine-n-ols is presented in Fig. 3

The $\mathrm{O}(\mathrm{n}) \mathrm{H}(\mathrm{n}=1,2,3,6)$ hydroxyl deprotonation involves various chief changes in the piperidine ring such as elongating the adjacent bonds. This effect can be assigned to hyperconjugation, i.e., the lone pairs (LP) delocalization of the deprotonated oxygen into the $\sigma^{*}$ antibonding orbitals of the following bonds: $\mathrm{C}(\mathrm{n})-\mathrm{H}, \mathrm{C}(\mathrm{n})-\mathrm{C}(\mathrm{n}-1)$ and $\mathrm{C}(\mathrm{n})$ $\mathrm{C}(\mathrm{n}+1)$. Second-order perturbation theory analysis employed for piperidine-2-ol(e) and piperidine-3-ol( $a)$ are given in Table 1S in Supporting Information (Tables introduced in Supporting Information are designated by S). As shown in Table 1S for piperidine-3-ol(a) compound, the delocalization interaction occurs through the $\mathrm{O} 3$ lone pair to $\sigma^{*}{ }_{\mathrm{C} 3-}$ ${ }_{\mathrm{H} 3}, \sigma^{*}{ }_{\mathrm{C} 3-\mathrm{C} 2}$ and $\sigma^{*}{ }_{\mathrm{C} 3-\mathrm{C} 4}$ antibonding orbitals (i.e. $\mathrm{n}_{\mathrm{O} 3} \rightarrow \sigma^{*}{ }_{\mathrm{C} 3-\mathrm{H} 3}, \mathrm{n}_{\mathrm{O} 3} \rightarrow \sigma^{*}{ }_{\mathrm{C} 3-\mathrm{C} 2}$ and $\mathrm{n}_{\mathrm{O} 2} \rightarrow \sigma^{*}{ }_{\mathrm{C} 3-\mathrm{C} 4}$ ) and the total charge transfer stabilization energies ( $\left.\mathrm{E}_{\text {sum }}^{2}\right)$ for this structure is $31.97 \mathrm{kcal}^{\mathrm{mol}}{ }^{-1}$. However, in the case of piperidine-2-ol(e), the delocalization interaction occurs through the $\mathrm{O} 2$ lone pair to $\sigma^{*} \mathrm{C2}-\mathrm{H} 2, \sigma^{*} \mathrm{C2}-\mathrm{Cl}$ and $\sigma^{*} \mathrm{C} 2-\mathrm{C} 3$ antibonding orbitals (i.e. $\mathrm{n}_{\mathrm{O} 2} \rightarrow \sigma^{*}{ }_{\mathrm{C} 2-\mathrm{H} 2}, \mathrm{n}_{\mathrm{O} 2} \rightarrow \sigma^{*}{ }_{\mathrm{C} 2-\mathrm{C} 1}$ and $\left.\mathrm{n}_{\mathrm{O} 2} \rightarrow \sigma^{*}{ }_{\mathrm{C} 2-\mathrm{C} 3}\right)$ with $\mathrm{E}_{\text {sum }}^{2}=30.00$. Based on these results, the piperidine-3-ol( $(a)$ is the strongest acid among the modeled piperidine-n-olsdepicted in Figure 3. In order to investigate the acidities of piperidine-1-ol, firstly understanding the acidities of the axial and equatorial hydroxyl groups is needed. Cooks and coworkers, in a study of the acidities of methyl cyclohexanols, observed that the axial hydroxyl groups are more acidic than equatorial hydroxyl groups [57] They demonstrated that both cis-2 and cis-4-methyl cyclohexanols are about 1 kcal.mol ${ }^{-1}$ more acidic than their relative trans configurations. In both cases, the trans configuration has an equatorial hydroxyl group while the cis configuration has an axial one. However, our calculations indicate that neutral equatorial piperidine-1-ol is calculated to be about $0.70 \mathrm{kcal}^{\mathrm{mol}}{ }^{-1}$ more stable than axial piperidine-1-ol. For the anions, equatorial is more stable than axial anion by $1.50 \mathrm{kcal}_{\mathrm{mol}}{ }^{-1}$. This gives an acidity distinction of $1.2 \mathrm{kcal}^{\mathrm{mol}}{ }^{-1}$.

The arrangement of the anomeric hydroxyl is guided by completion between the "exo-anomeric" and "negative charge" effect observed by Mulroney et al. [56]. A stereoelectronic element that persuades a sizeable obstacle to spin about the exocyclic $\mathrm{C}-\mathrm{O}$ bond at the anomeric center is defined as the exo-anomeric effect. Anomeric equatorial or axial hydroxyl groups favors the gauche conformation in which one of the lone pairs' electrons of exocyclic O1 oxygen are antipariplanar with the C1-N5 bond and consequently are delocalized into the endocyclic antibonding $\sigma^{*} \mathrm{Cl}$-N5 orbital. Instead, the negative charge effect may be observed as the inclination for the anomeric hydroxyl to involve in the cooperative hydrogen bonding convinced by a deprotonated hydroxyl and adopt a trans orientation. In the 
anomeric position (deprotonation of hydroxyl in piperidine-1-ol), the negative charge effect challenges the "endoanomeric" effect [58], which is originated by the interaction of the ring nitrogen lone pairs and the antibonding $\sigma^{*}{ }_{\mathrm{Cl}}$ o1 orbital. Calculated NBO interaction energies for negative charge effect $\left(\mathrm{n}_{\mathrm{O} 1} \rightarrow \sigma^{*} \mathrm{Cl}-\mathrm{N} 5\right)$ and "endo-anomeric" effect

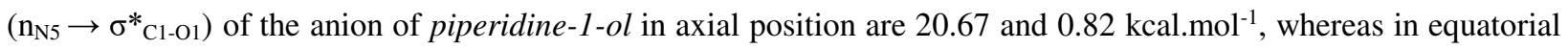
one these interaction energies are 21.51 and $0.52 \mathrm{kcal}^{\mathrm{mol}}{ }^{-1}$, respectively. Therefore, the negative charge effect balances the "endo-anomeric" effect, thus increases the C1-N5 bond length by $0.090 \AA$ and $0.071 \AA$, respectively; compared with neutral species.

\subsection{Relative gas-phase acidities (GPAs) of piperidine-diols}

The total and relative energies of the several systems investigated for the piperidine-diols are summarized in Table 2. The following absolute GPAs are also shown in this Table. As shown in Table 2, for 1,2-OH1 structures, the 1,2,ea$\mathrm{OH} 1$ is the most acidic compound and the following acidity order was achieved: 1,2,ea-OH1>1,2,ae-OH1>1,2,ee$\mathrm{OH1}>1,2, a a-\mathrm{OH} 1$. Moreover, for 1,2-OH2 structures, the following order of acidity was obtained: 1,2,ea$\mathrm{OH} 2>1,2, e e-\mathrm{OH} 2>1,2, \mathrm{aa}-\mathrm{OH} 2>1,2, a e-\mathrm{OH} 2$.

Table 2 Total energies (hartree), relative energies $\left(\mathrm{kcal} . \mathrm{mol}^{-1}\right), \Delta \mathrm{H}_{\text {acid }}\left(\mathrm{kcal}^{\mathrm{mol}}{ }^{-1}\right)$ and GPA $\left(\mathrm{kcal}^{\mathrm{mol}}{ }^{-1}\right)$ of different structures of piperidine-diols.

\begin{tabular}{|c|c|c|c|c|c|c|}
\hline \multirow{2}{*}{ piperidine-diols } & \multicolumn{2}{|c|}{ OH conformation } & \multirow{2}{*}{$\mathrm{E}$} & \multirow{2}{*}{$\Delta \mathrm{E}$} & \multirow{2}{*}{$\Delta \mathrm{H}_{\text {acid }}$} & \multirow{2}{*}{ GPA } \\
\hline & Neural & Anion & & & & \\
\hline \multirow[t]{2}{*}{$1,2, a a$} & $\mathrm{gg}^{-}$ & $\mathrm{xg}^{-}$ & -399.4051611 & 7.7 & 379.1 & 371.9 \\
\hline & $\mathrm{gg}^{-}$ & $\mathrm{gx}$ & -399.4058445 & 6.5 & 379.2 & 372.0 \\
\hline \multirow[t]{2}{*}{$1,2, e e$} & $\mathrm{gg}$ & $x g$ & -399.4163173 & 0.7 & 374.8 & 367.6 \\
\hline & gg & tx & -399.4133778 & 1.8 & 376.7 & 369.7 \\
\hline \multirow[t]{2}{*}{$1,2, a e$} & $\operatorname{tg}$ & $\mathrm{xg}$ & -399.4147363 & 1.7 & 374.0 & 366.6 \\
\hline & $\operatorname{tg}$ & $\mathrm{gx}$ & -399.394086 & 13.9 & 383.3 & 376.0 \\
\hline \multirow[t]{2}{*}{$1,2, e a$} & $\mathrm{~g}^{-} \mathrm{g}$ & $\mathrm{xg}^{-}$ & -399.4174553 & 0.0 & 370.6 & 363.7 \\
\hline & $g^{-} g$ & gx & -399.4161783 & 0.0 & 374.9 & 367.5 \\
\hline
\end{tabular}

The most stable structures obtained for neutral and anionic forms of piperidine-diols are presented in Fig. 4 The second hydroxyl group in diols raises the acidity of anomeric hydroxyl by ion-dipole interactions. When ion-dipole interactions are closer, they are stronger and also ion-dipole stabilization in the diaxial conformation is greater than the destabilization obtained from steric repulsions.

It is important to consider the role of the hydrogen bonds observed in the piperidine-diols. This can be done by computing the $\mathrm{E}^{2}\left[\mathrm{n}_{\mathrm{O}(\mathrm{n})} \rightarrow \sigma_{\mathrm{O}(\mathrm{n}+1)-\mathrm{H}(\mathrm{n}+1)}^{*}\right.$ and $\mathrm{E}^{2}\left[\mathrm{n}_{\mathrm{O}(\mathrm{n}+1)} \rightarrow \sigma_{\mathrm{O}(\mathrm{n})-\mathrm{H}(\mathrm{n})}^{*}\right](\mathrm{n}=1)$ NBO interaction energy for their corresponding anions. As shown in Table $2 \mathrm{~S}$, the $\mathrm{E}^{2}\left[\mathrm{LP}_{\mathrm{O} 1} \rightarrow \sigma^{*}{ }^{*} 2 \mathrm{H} 2\right]$ interaction energy obtained for anion of 1,2 ,ea$\mathrm{OHI}\left(16.45 \mathrm{kcal} . \mathrm{mol}^{-1}\right)$ is greater than the value computed for deprotonated forms of 1,2,ae-OHI and 1,2,ee-OHI structures. This arises from an extremely activated C1-N5 bond (1.518 $)$ ), which is lengthened by $0.061 \AA$ compared with neutral 1,2,ea. Consequently, the strong $\mathrm{O} 2-\mathrm{H} . . . \mathrm{O} 1$ hydrogen bond in the anion of 1,2,ea-OH1 decreases the 
extent of the negative charge effect and allows its stability. Contrarily, $\mathrm{E}^{2}$ values achieved for 1,2,ea-OH2 and 1,2,ee$\mathrm{OH} 2$ anions (16.76 and $8.96 \mathrm{kcal}^{\mathrm{mol}}{ }^{-1}$, respectively) indicate that the $\mathrm{E}^{2}$ value of 1,2,ea-OH2 anion is larger than the value calculated for the other compound. This result is confirmed by the corresponding $\Delta \mathrm{H}_{\text {acid }}$ and GPA values.

QTAIM analysis was also applied to elaborate the character of the hydrogen bonding interactions. The Laplacian of the electron density $\left(\nabla^{2} \rho(r)\right)$, the electron energy density $(H(r))$ and the electronic topological properties at H...Y BCPs (bond critical points) of intermolecular H-bonds containing electron density $(\rho(r))$, of all structures are outlined in Table 3.

Table 3 Electron densities $\left(\rho(r)\right.$, e/a.u $\left.u^{3}\right)$, theirs Laplacians $\left(\nabla^{2} \rho(r)\right.$, e/a.u $\left.u^{5}\right)$, kinetic energy densities G(r), potential energy densities $\mathrm{V}(\mathrm{r})$, electronic energy densities $\mathrm{H}(\mathrm{r})$, and hydrogen bond energies $\left(\mathrm{E}_{\mathrm{H} . . . \mathrm{x}}, \mathrm{kcal} / \mathrm{mol}\right)$ at bond critical points (BCPs) calculated at B3LYP/6-311++G (d,p) level for piperidine-diols.

\begin{tabular}{ccccccccc}
\hline System & BCP & $\rho(r)$ & $\nabla^{2} \rho(r)$ & $G(r)$ & $H(r)$ & $V(r)$ & $E_{H \ldots X}$ & $-G(r) / V(r)$ \\
\hline $1,2, a e-\mathrm{OH} 1$ & $\mathrm{O} 1-\mathrm{H} 2$ & 0.025 & 0.149 & 0.034 & 0.003 & -0.031 & 9.8 & 1.101 \\
$1,2, e a-\mathrm{OH} 1$ & $\mathrm{O} 1-\mathrm{H} 2$ & 0.031 & 0.199 & 0.047 & 0.003 & -0.044 & 13.8 & 1.067 \\
$1,2, e a-\mathrm{OH} 2$ & $\mathrm{O} 2-\mathrm{H} 1$ & 0.030 & 0.193 & 0.045 & 0.003 & -0.042 & 13.2 & 1.072 \\
$1,2, e e-\mathrm{OH} 1$ & $\mathrm{O} 1-\mathrm{H} 2$ & 0.021 & 0.113 & 0.026 & 0.003 & -0.023 & 7.2 & 1.122 \\
$1,2, e e-\mathrm{OH} 2$ & $\mathrm{O} 2-\mathrm{H} 1$ & 0.023 & 0.130 & 0.029 & 0.003 & -0.026 & 8.3 & 1.115 \\
\hline
\end{tabular}

Table 3 demonstrates that all hydrogen bonds in investigated compounds have positive $\nabla^{2} \rho(r)$ and $H(r)$ values. Thus, the hydrogen bonds are medium hydrogen bonds. The values of hydrogen bond energies $\left(\mathrm{E}_{\mathrm{H} . . . \mathrm{x}}\right)$ are summarized in Table 3. The highest hydrogen bond energies for 1,2- $\mathrm{OH} 1$ and 1,2-OH2 anions are seen for 1,2,ea- $\mathrm{OH} 1$ and 1,2,ea$\mathrm{OH} 2$ structures (13.8 and $13.2 \mathrm{kcal}^{\mathrm{mol}}{ }^{-1}$, respectively). These results acknowledge the results of orbital interaction energies $\left(E^{2}\right)$ for these hydrogen bonds (see Table $2 S$ ).

\subsection{Relative gas-phase acidities (GPAs) of iminosugars}

In this study, the GPAs of some of these compounds (Fig. 1) were studied using MP2/6-311++G(d,p)//B3LYP/6$311++\mathrm{G}(\mathrm{d}, \mathrm{p})$ calculations. For each structure, various primary and secondary hydroxyl groups were deprotonated. The total energies, relative energies and the resulting GPAs of the several structures investigated for the iminosugars are summarized in Table 4. The most acidic site of each compound shown in Fig. 1 is seen in $\alpha-1-O H 2, \beta-1-O H 2,2-O H 3$, 3-OH3, 5-OH4 and 6-OH2, structures. 
Table 4 Total energies (hartree), relative energies $\left(\mathrm{kcal}^{\mathrm{mol}}{ }^{-1}\right), \Delta \mathrm{H}_{\text {acidity }}\left(\mathrm{kcal} . \mathrm{mol}^{-1}\right)$ and GPA $\left(\mathrm{kcal} . \mathrm{mol}^{-1}\right)$ of different structures of iminosugars.

\begin{tabular}{|c|c|c|c|c|c|c|}
\hline \multirow{2}{*}{ iminosugars } & \multicolumn{2}{|c|}{$\mathrm{OH}$ conformation } & \multirow{2}{*}{ E } & \multirow{2}{*}{$\Delta \mathrm{E}$} & \multirow{2}{*}{$\Delta \mathrm{H}_{\text {acid }}$} & \multirow{2}{*}{ GPA } \\
\hline & Neural & Anion & & & & \\
\hline \multirow[t]{3}{*}{3} & $\mathrm{gg}^{-\mathrm{T}}$ & $\mathrm{xg}^{-} \mathrm{G}^{-}$ & -513.3178 & 0.5 & 379.0 & 371.8 \\
\hline & $\mathrm{gg}^{-\mathrm{T}}$ & $\mathrm{gxG}^{-}$ & -513.3186 & 0.0 & 378.6 & 371.1 \\
\hline & $\mathrm{gg}^{-\mathrm{T}}$ & $\operatorname{gg}^{-} X$ & -513.3114 & 4.5 & 382.1 & 375.1 \\
\hline \multirow[t]{4}{*}{2} & $\mathrm{gg}^{-} \mathrm{gG}$ & $\mathrm{xg}^{-} \mathrm{gG}$ & -588.2126 & 0.6 & 369.0 & 361.9 \\
\hline & $\mathrm{gg}^{-} \mathrm{gG}$ & $\operatorname{txgG}$ & -588.2136 & 0.0 & 369.0 & 361.3 \\
\hline & $\mathrm{gg}^{-} \mathrm{gG}$ & $g^{-} x G$ & -588.2101 & 2.2 & 370.4 & 363.3 \\
\hline & $\mathrm{gg}^{-} \mathrm{gG}$ & $\operatorname{gg}^{-} \mathrm{gX}$ & -588.1998 & 8.6 & 377.6 & 370.3 \\
\hline \multirow[t]{4}{*}{5} & gg-tT & $x^{-} g G$ & -588.2229 & 5.2 & 364.3 & 358.3 \\
\hline & $g^{-1} \mathrm{tT}$ & $\operatorname{gxgT}$ & -588.2153 & 10.0 & 371.1 & 364.5 \\
\hline & $g^{-1 T}$ & $g^{-} x G$ & -588.2313 & 0.0 & 359.8 & 354.0 \\
\hline & $g^{-1} \mathrm{tT}$ & $g^{-} t X$ & -588.2226 & 5.4 & 364.9 & 359.7 \\
\hline \multirow[t]{4}{*}{6} & $g^{-} g^{-} g G^{-}$ & $\mathrm{xg}^{-} \mathrm{gG}^{-}$ & -588.2226 & 0.0 & 370.2 & 362.9 \\
\hline & $g^{-} g^{-} g G^{-}$ & $\operatorname{gxgG}^{-}$ & -588.2010 & 13.5 & 383.4 & 375.5 \\
\hline & $\mathrm{g}^{-} \mathrm{g}^{-} \mathrm{gG}-$ & $\operatorname{gg}^{-} \mathrm{xG}^{-}$ & -588.2064 & 10.1 & 379.7 & 371.5 \\
\hline & $\mathrm{g}^{-} \mathrm{g}^{-} \mathrm{gG}^{-}$ & $\operatorname{gg}^{-} \mathrm{gX}$ & -588.2102 & 7.7 & 377.4 & 370.4 \\
\hline \multirow[t]{5}{*}{$\alpha-1$} & $\mathrm{~g}^{-} \mathrm{g}^{-} \mathrm{ggG}^{-}$ & $\mathrm{xg}^{-} \mathrm{ggG}^{-}$ & -663.1274 & 1.5 & 360.8 & 353.9 \\
\hline & $\mathrm{g}^{-} \mathrm{g}^{-} g \mathrm{gG} \mathrm{G}^{-}$ & $\operatorname{txggG}{ }^{-}$ & -663.1299 & 0.0 & 359.2 & 352.6 \\
\hline & $\mathrm{g}^{-} \mathrm{g}^{-} \mathrm{ggG}^{-}$ & $\operatorname{ttxgG}{ }^{-}$ & -663.1289 & 0.6 & 359.9 & 353.5 \\
\hline & $\mathrm{g}^{-} \mathrm{g}^{-} \mathrm{ggG}^{-}$ & $g^{-} g^{-t x T}$ & -663.1123 & 11.0 & 369.5 & 364.0 \\
\hline & $\mathrm{g}^{-} \mathrm{g}^{-} \mathrm{ggG}^{-}$ & $\mathrm{ttttX}$ & -663.1257 & 2.6 & 360.6 & 355.5 \\
\hline \multirow[t]{5}{*}{$\beta-1$} & $\operatorname{tg}^{-} g g G^{-}$ & $\mathrm{xgggG}^{-}$ & -663.1270 & 2.8 & 358.4 & 351.6 \\
\hline & $\operatorname{tg}^{-} g^{\prime} G^{-}$ & $\operatorname{txggG} G^{-}$ & -663.1314 & 0.0 & 356.0 & 349.4 \\
\hline & $\operatorname{tg}^{-} g^{-} G^{-}$ & $\operatorname{ttxgT}$ & -663.1309 & 0.3 & 356.3 & 349.8 \\
\hline & $\operatorname{tg}^{-} \operatorname{ggG}^{-}$ & $\mathrm{tttxG}$ & -663.1146 & 10.6 & 365.9 & 358.1 \\
\hline & $\operatorname{tg}^{-} g^{-} G^{-}$ & $\mathrm{gtttX}$ & -663.1085 & 14.3 & 369.0 & 361.9 \\
\hline
\end{tabular}

The computed $\Delta \mathrm{H}_{\text {acid }}$ and GPA values of iminosugars are given in Table 4 . All H...O distances close to $2.5 \AA$ were classified as possible hydrogen bonds. As predicted, the most stable structures for the alkoxides have five intramolecular hydrogen bonds (Fig. 5).

The anticipated GPAs for $\alpha-\mathbf{1 - O H} 2$ and $\beta$-1-OH2 are 352.6 and $349.4 \mathrm{kcal}^{-\mathrm{mol}^{-1}}$, respectively. These values are relative to the heterolytic RO-H bond dissociation energies, so the smaller number the more acidic compound. In $\beta$ 1- $\mathrm{OH} 2$, two $\mathrm{OH}$ substituents interact with the alkoxide center through hydrogen bonds. The three donor sites on the negatively charged oxygen atom center, thus, are utilized. This bonding order can be observed as supplying the first solvation shell for the ion, but a second shell might be included by exchanging extra hydroxyl groups within the molecule that can interact with the electron rich oxygen atoms of the first solvation shell. As shown in Table 4, for 
iminosugars, the $\beta-\mathbf{1}-\mathrm{OH} 2$ is the most acidic structure and the resulting sequence of acidity was obtained: $\beta$-1-OH2> $\alpha-1-O H 2>5-O H 4>2-O H 3>6-O H 2>3-O H 3$.

As discussed in section 3.2., the $\mathrm{O}(\mathrm{n}) \mathrm{H}(\mathrm{n}=2-6)$ hydroxyl deprotonation brings about various main changes in the piperidinic ring such as elongating the neighboring bonds. This effect can be owing to hyperconjugation. As shown in Table 3S, for $\beta-1-O H 2$ anion, the delocalization interaction happens through the $\mathrm{O} 2$ lone pair to $\sigma^{*}{ }_{\mathrm{C} 2-\mathrm{H} 2,} \sigma^{*} \mathrm{C} 2 \mathrm{Cl}$ and

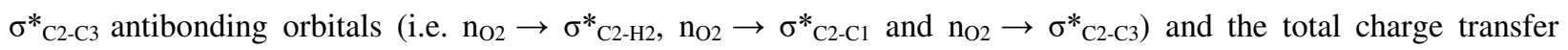

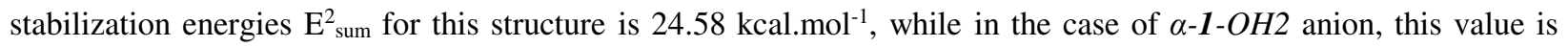
$23.36 \mathrm{kcal}^{\mathrm{mol}}{ }^{-1}$. Based on these results, among azasugars examined here, the $\beta-1-O H 2$ is the strongest acid. It's worth mentioning that these results obtained from $\mathrm{E}^{2}$ values are in agreement with GPAs' (see Table 4 for more details).

\subsection{Theoretical $\mathrm{p} K_{\mathrm{a}}$ values in DMSO}

One of the basic procedures in chemistry and biology is proton transfer. Therefore, the comprehension and anticipation of the thermodynamics of a proton transfer reaction and the separation constants of acids and bases in several solvents are of critical significance in many fields of biochemistry and chemistry. Nowadays, experimental quantification of aqueous phase $\mathrm{pK}_{\mathrm{a}}$ values has become an economical standard administration [59]. ${ }^{58}$ About the measurement of $\mathrm{p} K_{\mathrm{a}}$ values in nonaqueous solvents, the same cannot be said. Moreover, wide category of chemicals that are not readily persuadable to experimental identification exist (e.g., intermediates of reaction, highly potent and very weak acids or bases with a $\mathrm{p} K_{\mathrm{a}}$ outer the "natural" $\mathrm{p} K_{\mathrm{a}}$ range that can be accessibly measured). Thus, substantial attempt has been allocated to expand the first main forecast methods for $\mathrm{p} K_{\mathrm{a}}$ values. Hydrogen bonds are the superior pattern for arranging the three-dimensional structures of biomolecules. This effect is pointless in water and other protic solvents, but a similar stabilization is anticipated in hydrophobic surroundings such as in an enzyme site or dimethyl sulfoxide (DMSO) as a nonprotic solvent.

Similar gas phase results are predicted in nonprotic solvents, but solvation will decrease the measure of the acidity enhancements. To test this hypothesis, the $\mathrm{p} K_{\mathrm{a}}$ 's of some polyhydroxylated thiopyrans were calculated using one reference acid in DMSO. The coming $\mathrm{p} K_{\mathrm{a}}$ values were established to lessen with the addition of each hydroxyl group (Table 5) and the acidity value increases as predicted based on gas-phase calculations. Structure $\beta-1-O H 2$ is $8.0 \mathrm{p} K_{\mathrm{a}}$ units more acidic than 1-propanol, and this specifies that the conjugate base of the former acid is stabilized in DMSO by the attendance of intramolecular hydrogen bonds. Consequently, $\beta-1-O H 2$ is almost as acidic as 2,2,2trifluoroethanol $\left(\mathrm{p} K_{\mathrm{a}}\left(\mathrm{CF}_{3} \mathrm{CH}_{2} \mathrm{OH}\right)=23.5\right)$.

Table 5 The values of GPA (in kcal.mol ${ }^{-1}$ ), and $\mathrm{p} K_{\mathrm{a}}$ for deprotonation of polyhydroxylated piperidines at $298 \mathrm{~K}$.

\begin{tabular}{cccccccc}
\hline Name & GPA & $\mathrm{p} K_{\mathrm{a}}$ & $\Delta \mathrm{p} K_{\mathrm{a}}$ & Name & GPA & $\mathrm{p} K_{\mathrm{a}}$ & $\Delta \mathrm{p} K_{\mathrm{a}}$ \\
& & & & & & & \\
\hline 1-propanol & 379.9 & $30.0^{\mathrm{a}}$ & 0.0 & $1,2, e e-O H 2$ & 369.7 & 27.7 & -2.3 \\
piperidine-1-ol (a) & 377.3 & 29.9 & -0.1 & 1,2, ae-OH1 & 363.7 & 25.6 & -4.4
\end{tabular}




\begin{tabular}{|c|c|c|c|c|c|c|}
\hline (e) & 376.1 & 27.9 & -2.1 & $1,2, a e-\mathrm{OH} 2$ & 376.0 & 28.2 \\
\hline piperidine-2-ol (a) & 374.0 & 30.0 & 0.0 & 1,2,ea-OHI & 366.6 & 25.7 \\
\hline (e) & 374.9 & 28.0 & -2.0 & 1,2,ea-OH2 & 367.5 & 27.3 \\
\hline piperidine-3-ol (a) & 373.9 & 29.3 & -0.7 & $3-\mathrm{OH} 3$ & 371.1 & 27.9 \\
\hline (e) & 375.9 & 28.8 & -1.2 & 2-OH3 & 361.3 & 23.8 \\
\hline piperidine-6-ol (a) & 375.7 & 30.7 & 0.7 & $5-\mathrm{OH} 4$ & 354.0 & 22.5 \\
\hline (e) & 375.8 & 30.5 & 0.5 & 6-OH2 & 362.9 & 25.2 \\
\hline 1,2,aa-OH1 & 371.9 & 28.0 & -2.0 & $\alpha-1-O H 2$ & 352.6 & 22.5 \\
\hline $1,2, a a-O H 2$ & 372.0 & 28.3 & -1.7 & $\beta-1-O H 2$ & 349.4 & 22.0 \\
\hline 1,2,ee-OH1 & 367.6 & 25.8 & -4.2 & & & \\
\hline
\end{tabular}

${ }^{\mathrm{a}} \mathrm{An}$ estimated value based on the literature $\mathrm{p} K_{\mathrm{a}}$ for 1-propanol $(30.0)$ [60].

If one schemes the $\mathrm{p} K_{\mathrm{a}}$ values for some structures shown in Table 5 versus their computed gas-phase acidities (GPAs) (Fig. 6), gives a straight line ( $\left.\mathrm{p} K_{\mathrm{a}}=0.272 \mathrm{GPA}-73.81 \mathrm{kcal}^{\mathrm{mol}}{ }^{-1}, \mathrm{r}^{2}=0.946\right)$. The correlation between GPA and DMSO $\mathrm{p} K_{\mathrm{a}}$ values suggests that the acid strength increases by adding each hydroxyl group.

\section{Conclusions}

The MP2/6-311++G(d,p)//B3LYP/6-311++G(d,p) method gives reliable absolute gas-phase acidities. In the case of piperidine-n-ols, the piperidine-3-ol (a) was found to be the most acidic compound. NBO analysis verifies that the abundant effects (negative charge, exo- and endo-anomeric) and hyperconjugation are responsible for the hydroxyl order. In the case of piperidine-diols, QTAIM (quantum theory of atoms in molecules) analysis was also applied to elaborate the nature of the hydrogen bonding interactions. The results demonstrate that all hydrogen bonds in structures have positive $\nabla^{2} \rho(r)$ and $H(r)$ values. Thus, the hydrogen bonds are medium.

The $\mathrm{p} K_{\mathrm{a}}$ values of investigated compounds in DMSO were computed through a thermodynamic cycle, using Gibbs free energies of dissociation in DMSO solution as calculated by MP2/6-31+G(d,p)//B3LYP/6-31+(d) method. The range of $\mathrm{p} K_{\mathrm{a}}$ is between 30.7 and $22.0 \mathrm{kcal}^{\mathrm{mol}}{ }^{-1}$ (see Table 5 for more details). With this method, organized researches of several types of polyhydroxylated piperidines in DMSO were computed. These $\mathrm{p} K_{\mathrm{a}}$ values will be supportive to synthetic chemists to design experimental conditions for controlling deprotonated iminosugars. The results show that GPA and $\mathrm{p} K_{\mathrm{a}}$ values decrease with the addition of each hydroxyl group and thus the acid strength increases as predicted based upon the gas-phase calculations. For instance, $\beta-1-O H 2$ is $8.0 \mathrm{p} K_{\mathrm{a}}$ units more acidic than 1-propanol and this indicate that in the presence of intramolecular hydrogen bonds, the conjugate base of the prior acid is maintained in 
DMSO. Based on these $\mathrm{p} K_{\mathrm{a}}$ values, a discussion in connections with hydrogen acidities and molecular structures was reported.

Acknowledgment. Support from Tehran Medical Sciences, Islamic Azad University is gratefully acknowledged.

\section{Declarations}

Funding: The author received no specific funding for this work.

Conflicts of interest/Competing interests: The author has declared that no competing interests exist.

Ethics approval: N/A

Consent to participate: N/A

Consent for publication: N/A

Availability of data and material: The datasets used and/or analyzed during the current study are available from the corresponding author on reasonable request.

Code availability: N/A

Authors' contributions: N/A

\section{References}

[1] K. Afarinkia, A. Bahar, Recent advances in the chemistry of azapyranose sugars, Tetrahedron: Asymmetry, 16 (2005) 1239-1287.

[2] L.O.B. Zamoner, V. Aragão-Leoneti, I. Carvalho, Iminosugars: Effects of Stereochemistry, Ring Size, and NSubstituents on Glucosidase Activities, Pharmaceuticals, 12 (2019) 108.

[3] J.L. Jensen, S.C. Tsuang, A.H. Uslan, Mechanism of acid-catalyzed anomerization of methyl D-glucopyranosides, The Journal of Organic Chemistry, 51 (1986) 816-819.

[4] P.S. Liu, Total synthesis of 2,6-dideoxy-2,6-imino-7-O-(.beta.-D-glucopyranosyl)-D-glycero-L-gulo-heptitol hydrochloride. A potent inhibitor of .alpha.-glucosidases, The Journal of Organic Chemistry, 52 (1987) 4717-4721.

[5] A. Cogoli, G. Semenza, A probable oxocarbonium ion in the reaction mechanism of small intestinal sucrase and isomaltase, Journal of Biological Chemistry, 250 (1975) 7802-7809.

[6] M.L. Sinnott, Catalytic mechanism of enzymic glycosyl transfer, Chemical Reviews, 90 (1990) 1171-1202.

[7] C.R. Johnson, A. Golebiowski, H. Sundram, M.W. Miller, R.L. Dwaihy, Synthesis of (+)-1deoxygalactonojirimycin and a related indolizidine, Tetrahedron Letters, 36 (1995) 653-654.

[8] K. Suzuki, H. Hashimoto, Synthesis of azapyranosyl thioglycoside: Novel pseudo-disaccharide having an azasugar residue at the non-reducing end, Tetrahedron Letters, 35 (1994) 4119-4122.

[9] G. Pandey, K.C. Bharadwaj, M.I. Khan, K. Shashidhara, V.G. Puranik, Synthesis of polyhydroxy piperidines and their analogues: a novel approach towards selective inhibitors of $\alpha$-glucosidase, Organic $\&$ biomolecular chemistry, 6 (2008) 2587-2595.

[10] S. Inouye, T. Tsuruoka, T. Ito, T. Niida, Structure and synthesis of nojirimycin, Tetrahedron, 24 (1968) 21252144. 
[11] S. Inouye, T. Tsuruoka, T. Nida, The structure of nojirimycin, a piperidinose sugar antibiotic, The Journal of antibiotics, 19 (1966) 288-292.

[12] B. Junge, M. Matzke, J. Stltefuss, Handbook of Experimental Pharmacology, Kuhlmann, J, (1996).

[13] H. Wang, Y. Shen, L. Zhao, Y. Ye, 1-Deoxynojirimycin and its derivatives: A mini review of the literature, Current medicinal chemistry, 28 (2021) 628-643.

[14] G. Pandey, M. Kapur, M.I. Khan, S.M. Gaikwad, A new access to polyhydroxy piperidines of the azasugar class: synthesis and glycosidase inhibition studies, Organic \& biomolecular chemistry, 1 (2003) 3321-3326.

[15] Y. Miyake, M. Ebata, Isolation and properties of a new $\beta$-galactosidase inhibitor, galactostatin, from Streptomyces lydicus, Agricultural and biological chemistry, 52 (1988) 153-158.

[16] Y. Miyake, M. Ebata, Inhibition of $\beta$-galactosidase by galactostatin, galactostatin-lactam, and 1deoxygalactostatin, Agricultural and biological chemistry, 52 (1988) 1649-1654.

[17] G. Legler, S. Pohl, Synthesis of 5-amino-5-deoxy-D-galactopyranose and 1, 5-dideoxy-1, 5-imino-D-galactitol, and their inhibition of $\alpha$-and $\beta$-D-galactosidases, Carbohydrate research, 155 (1986) 119-129.

[18] N. Asano, S. Ishii, H. Kizu, K. Ikeda, K. Yasuda, A. Kato, O.R. Martin, J.Q. Fan, In vitro inhibition and intracellular enhancement of lysosomal $\alpha$-galactosidase A activity in Fabry lymphoblasts by 1deoxygalactonojirimycin and its derivatives, European Journal of Biochemistry, 267 (2000) 4179-4186.

[19] G. Legler, A.E. Stütz, H. Immich, Synthesis of 1, 5-dideoxy-1, 5-imino-D-arabinitol (5-nor-L-fuco-1deoxynojirimycin) and its application for the affinity purification and characterisation of $\alpha$-L-fucosidase, Carbohydrate research, 272 (1995) 17-30.

[20] Y. Le Merrer, L. Poitout, J.-C. Depezay, I. Dosbaa, S. Geoffroy, M.-J. Foglietti, Synthesis of azasugars as potent inhibitors of glycosidases, Bioorganic \& medicinal chemistry, 5 (1997) 519-533.

[21] H. Nazır, M. Yıldız, H. Yılmaz, M. Tahir, D. Ülkü, Intramolecular hydrogen bonding and tautomerism in Schiff bases. Structure of N-(2-pyridil)-2-oxo-1-naphthylidenemethylamine, Journal of Molecular Structure, 524 (2000) 241250.

[22] M. Čuma, S. Scheiner, T. Kar, Competition between rotamerization and proton transfer in ohydroxybenzaldehyde, Journal of the American Chemical Society, 120 (1998) 10497-10503.

[23] A. Filarowski, T. Głowiaka, A. Koll, Strengthening of the intramolecular O $\cdots \mathrm{H} \cdots \mathrm{N}$ hydrogen bonds in Schiff bases as a result of steric repulsion, Journal of molecular structure, 484 (1999) 75-89.

[24] H. Raissi, E. Moshfeghi, A.F. Jalbout, M. Saeid Hosseini, M. Fazli, An approach to estimate the energy and strength of the intramolecular hydrogen bond in different conformers of 4-methylamino-3-penten-2-one, International Journal of Quantum Chemistry, 107 (2007) 1835-1845.

[25] M. Fores, S. Scheiner, Effects of chemical substitution upon excited state proton transfer. Fluoroderivatives of salicylaldimine, Chemical physics, 246 (1999) 65-74.

[26] C. Chen, S.F. Shyu, F.S. Hsu, Theoretical study of salicylaldehyde conformal isomers and their intramolecular oxygen and hydrogen relations, International journal of quantum chemistry, 74 (1999) 395-404. 
[27] V. Barone, A. Palma, N. Sanna, Toward a reliable computational support to the spectroscopic characterization of excited state intramolecular proton transfer:[2, 2'-bipyridine]-3, 3'-diol as a test case, Chemical physics letters, 381 (2003) 451-457.

[28] A.F. Jalbout, F. Contreras-Torres, R.D. Castillo, Solvation of excess electrons trapped in charge pockets on hydrated molecular surfaces, International Journal of Quantum Chemistry, 108 (2008) 567-575.

[29] G. Chung, O. Kwon, Y. Kwon, Theoretical study on salicylaldehyde and 2-mercaptobenzaldehyde: intramolecular hydrogen bonding, The Journal of Physical Chemistry A, 102 (1998) 2381-2387.

[30] P.J. Linstrom, W.G. Mallard, The NIST Chemistry WebBook: A chemical data resource on the internet, Journal of Chemical \& Engineering Data, 46 (2001) 1059-1063.

[31] K.M. Ervin, V.F. DeTuri, Anchoring the gas-phase acidity scale, The Journal of Physical Chemistry A, 106 (2002) 9947-9956.

[32] G. Ellison, P. Engelking, W. Lineberger, Photoelectron spectroscopy of alkoxide and enolate negative ions, The Journal of Physical Chemistry, 86 (1982) 4873-4878.

[33] P. Pérez, A. Toro-Labbé, R. Contreras, Global and local analysis of the gas-phase acidity of haloacetic acids, The Journal of Physical Chemistry A, 104 (2000) 5882-5887.

[34] P. Pérez, Y. Simon-Manso, A. Aizman, P. Fuentealba, R. Contreras, Empirical energy- density relationships for the analysis of substituent effects in chemical reactivity, Journal of the American Chemical Society, 122 (2000) 47564762.

[35] H. Dai, J. Kong, C. Zhou, N. Franklin, T. Tombler, A. Cassell, S. Fan, M. Chapline, Controlled chemical routes to nanotube architectures, physics, and devices, ACS Publications, 1999.

[36] P.R. Rablen, Is the acetate anion stabilized by resonance or electrostatics? A systematic structural comparison, Journal of the American Chemical Society, 122 (2000) 357-368.

[37] J.I. Brauman, L.K. Blair, Gas-phase acidities of alcohols, Journal of the American Chemical Society, 92 (1970) 5986-5992.

[38] Z. Tian, A. Fattahi, L. Lis, S.R. Kass, Single-centered hydrogen-bonded enhanced acidity (SHEA) acids: a new class of brønsted acids, Journal of the American Chemical Society, 131 (2009) 16984-16988.

[39] Spartan 06V102, Wavefunction, Inc., Irvine, CA, USA (2004).

[40] A.D. Beck, Density-functional thermochemistry. III. The role of exact exchange, J. Chem. Phys, 98 (1993) 5648 5646.

[41] C. Lee, W. Yang, R.G. Parr, Development of the Colle-Salvetti correlation-energy formula into a functional of the electron density, Physical review B, 37 (1988) 785.

[42] D. Xing, X. Tan, X. Chen, Y. Bu, Theoretical Study on the Gas-Phase Acidity of Multiple Sites of Cu+- Adenine and Cu2+- Adenine Complexes, The Journal of Physical Chemistry A, 112 (2008) 7418-7425.

[43] F. Ding, J.M. Smith, H. Wang, First-principles calculation of pKa values for organic acids in nonaqueous solution, The Journal of organic chemistry, 74 (2009) 2679-2691.

[44] A.E. Reed, F. Weinhold, Natural localized molecular orbitals, The Journal of chemical physics, 83 (1985) 17361740. 
[45] A.E. Reed, F. Weinhold, Natural bond orbital analysis of near-Hartree-Fock water dimer, The Journal of chemical physics, 78 (1983) 4066-4073.

[46] A.E. Reed, R.B. Weinstock, F. Weinhold, Natural population analysis, The Journal of Chemical Physics, 83 (1985) 735-746.

[47] A.J. Foster, F. Weinhold, Natural hybrid orbitals, Journal of the American Chemical Society, 102 (1980) 7211 7218.

[48] J. Chocholoušová, V. Špirko, P. Hobza, First local minimum of the formic acid dimer exhibits simultaneously red-shifted $\mathrm{O}-\mathrm{H} \cdots \mathrm{O}$ and improper blue-shifted $\mathrm{C}-\mathrm{H} \cdots \mathrm{O}$ hydrogen bonds, Physical Chemistry Chemical Physics, 6 (2004) 37-41.

[49] R. Bader, Atoms in Molecules: A Quantum Theory Oxford University, Press: Oxford,, nº UK, (1990).

[50] P.L.A. Popelier, F. Aicken, S. O’Brien, Atoms in molecules, Prentice Hall Manchester2000.

[51] A. Becke, The quantum theory of atoms in molecules: from solid state to DNA and drug design, John Wiley \& Sons2007.

[52] U. Koch, P.L. Popelier, Characterization of CHO hydrogen bonds on the basis of the charge density, The Journal of Physical Chemistry, 99 (1995) 9747-9754.

[53] R.F. Bader, A bond path: a universal indicator of bonded interactions, The Journal of Physical Chemistry A, 102 (1998) 7314-7323.

[54] R. Bader, F. Biegler-König, J. Schönbohm, AIM2000 program package, Ver. 2.0, McMaster University, Hamilton, (2002).

[55] C.J. Cramer, D.G. Truhlar, Quantum chemical conformational analysis of glucose in aqueous solution, Journal of the American Chemical Society, 115 (1993) 5745-5753.

[56] B. Mulroney, J. Barrie Peel, J.C. Traeger, Relative gas-phase acidities of glucopyranose from molecular orbital calculations, Journal of mass spectrometry, 34 (1999) 544-553.

[57] T.K. Majumdar, F. Clairet, J.C. Tabet, R.G. Cooks, Epimer distinction and structural effects on gas-phase acidities of alcohols measured using the kinetic method, Journal of the American Chemical Society, 114 (1992) 2897-2903.

[58] J. Edward, Stability of glycosides to acid hydrolysis, Chemistry and industry, 3 (1955) 1102-1104.

[59] A. Albert, E. Serjeant, The Determination of Ionization Constants: A Laboratory Manual, Chapman and Hall, London and New York, (1984).

[60] R. Stewart, The proton: applications to organic chemistry, Elsevier 2012. 
Figures

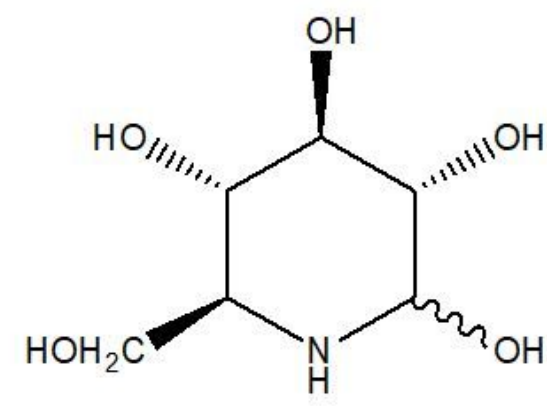

1

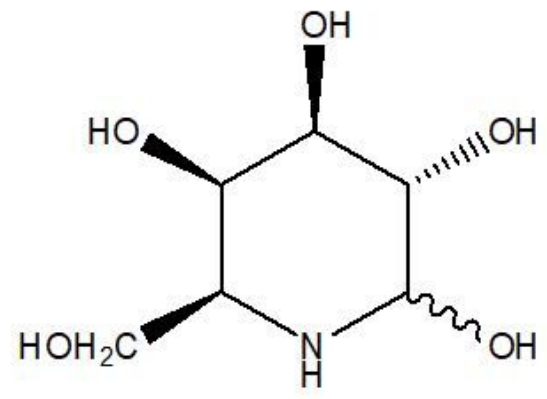

4

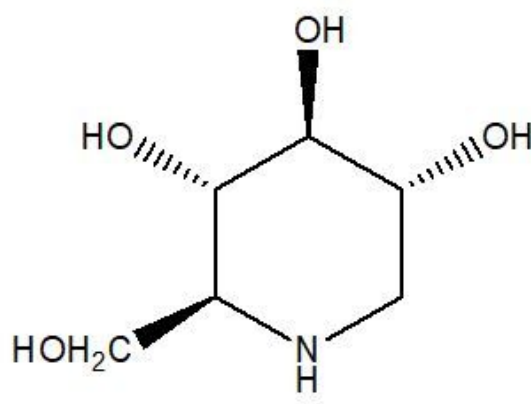

2

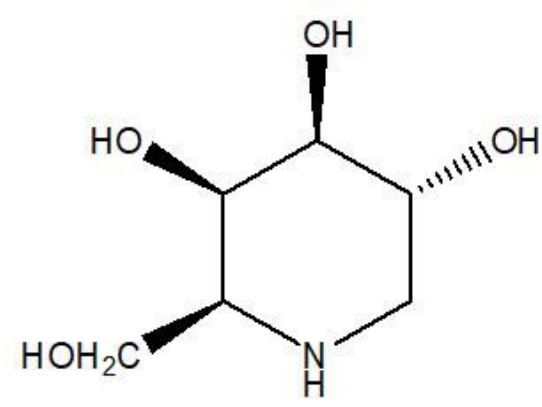

5

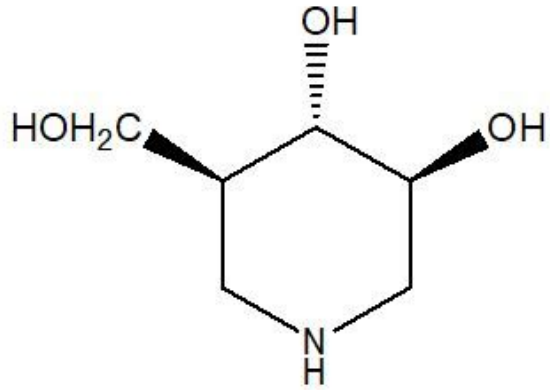

3

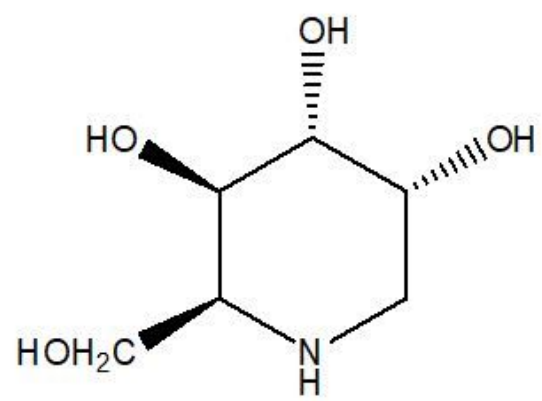

6

Figure 1

Glycosidase inhibitors with the 1-deoxy-azasugars structure 


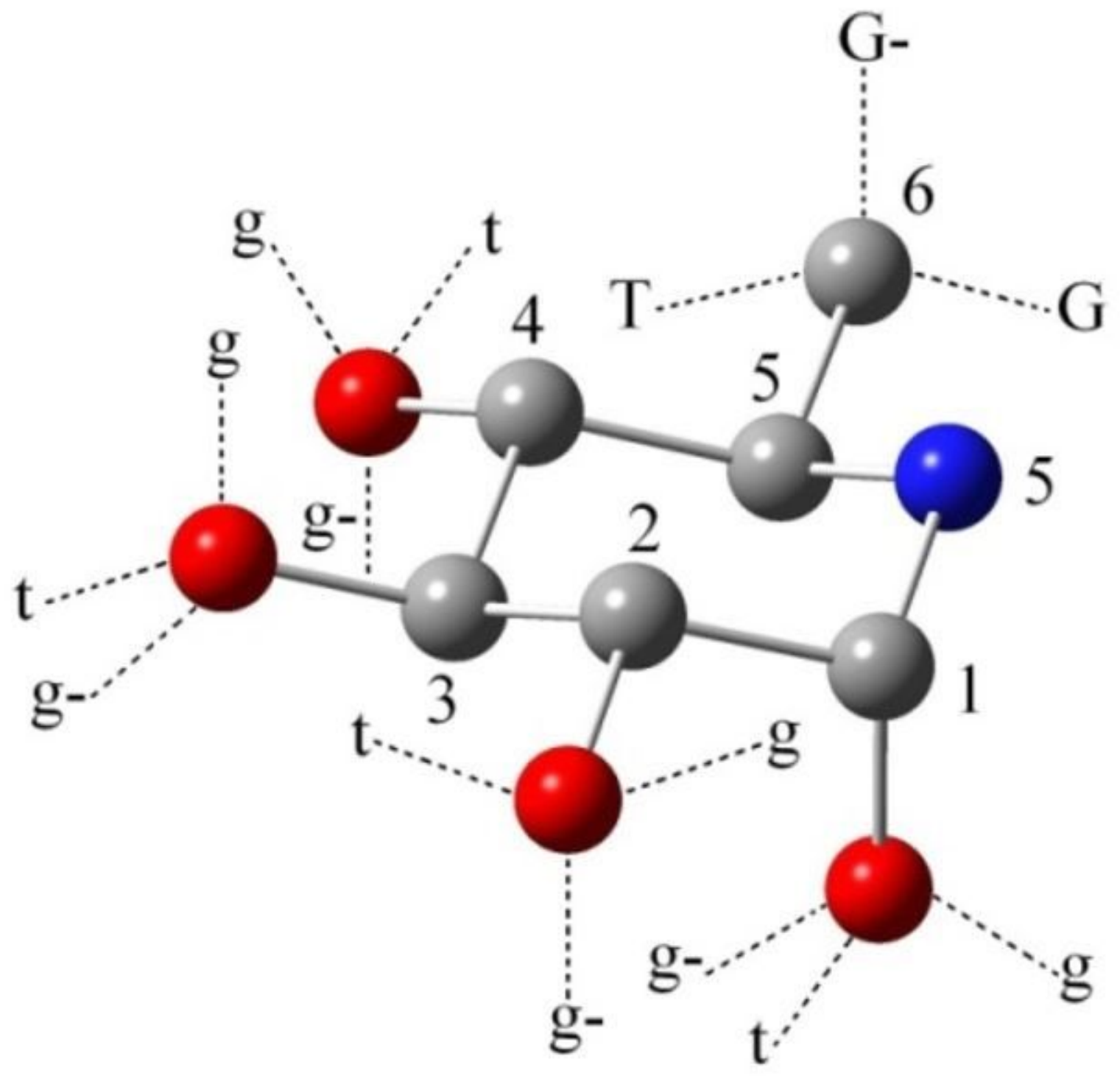

Figure 2

Illustration of the conventions for ring numbering and the exocyclic carbon labeling of rotamers of polyhydroxylated piperidine models 


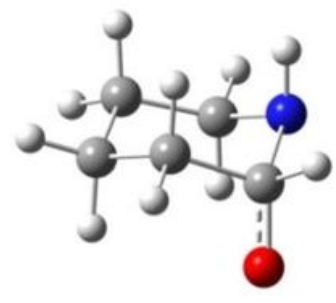

piperidine-1-ol(a)

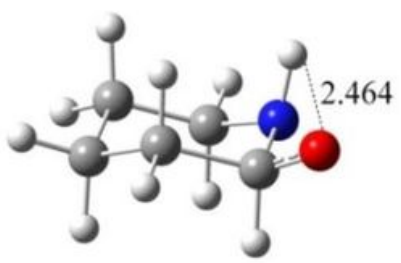

piperidine-1-ol(e)

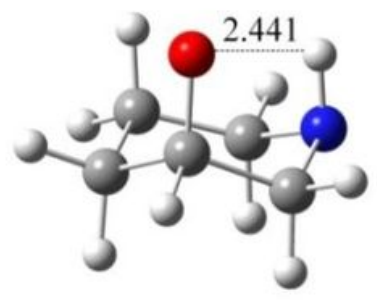

piperidine-2-ol(a)

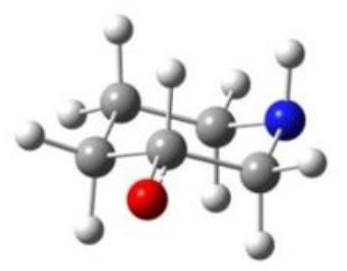

piperidine-2-ol(e)

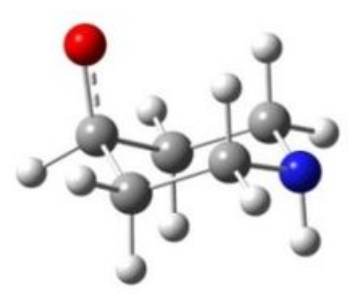

piperidine-3-ol(a)

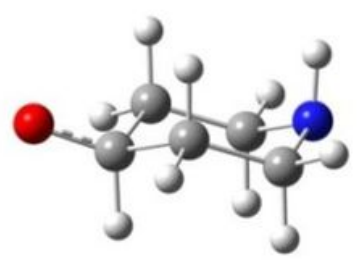

piperidine-3-ol(e)

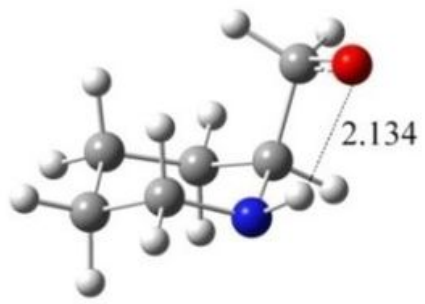

piperidine-6-ol(a)

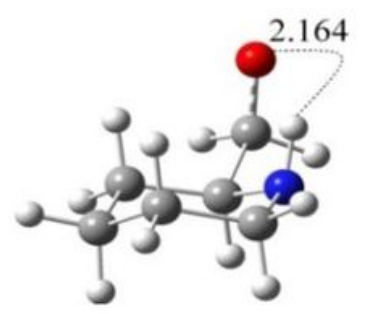

piperidine-6-ol(e)

Figure 3

MP2/6-311++G(d,p)//B3LYP/6-311++G(d,p) geometries of the lowest energy structures of deprotonated piperidine-n-ols 


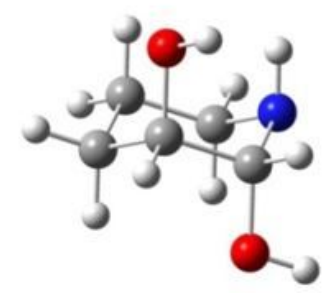

$1,2, a a$

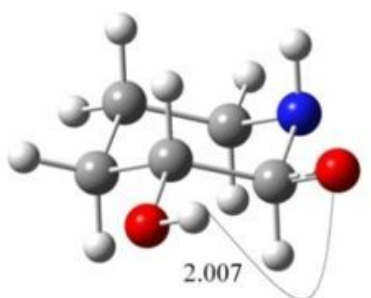

1,2,ee-OH1

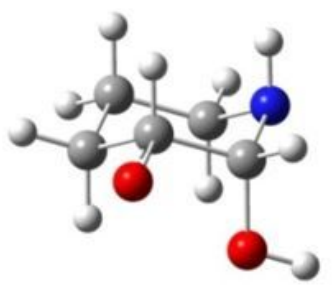

1,2,ae-OH2

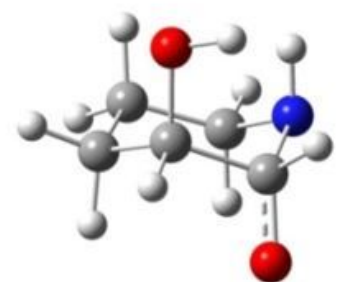

1,2,aa-OH1

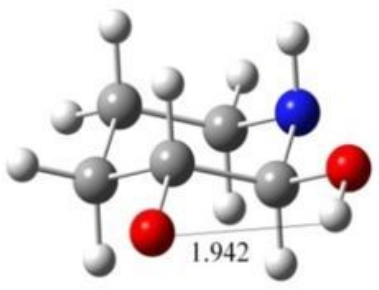

$1,2, e e-O H 2$

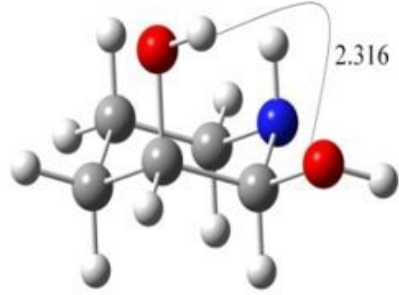

$1,2, e a$

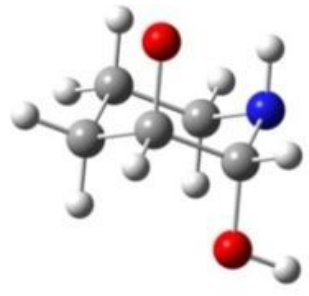

1,2,aa-OH2

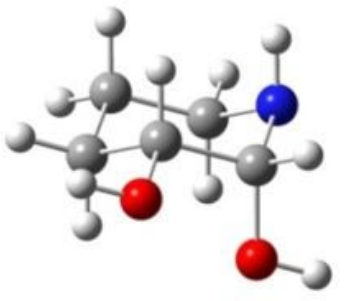

1,2 ae

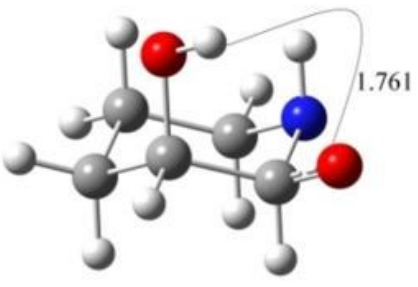

1,2,ea-OH1

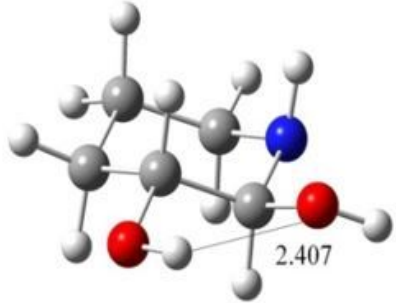

1,2 ,ee

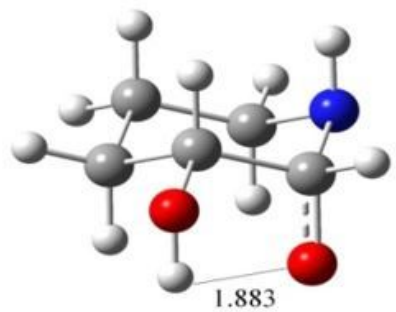

1,2,ae-OH1

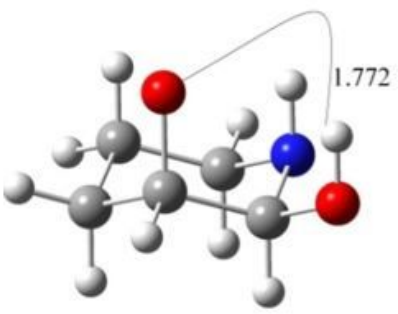

1,2,ea-OH2

\section{Figure 4}

MP2/6-311++G(d,p)//B3LYP/6-311++G(d,p) geometries of the lowest energy structures of neutral and deprotonated piperidine-diols 

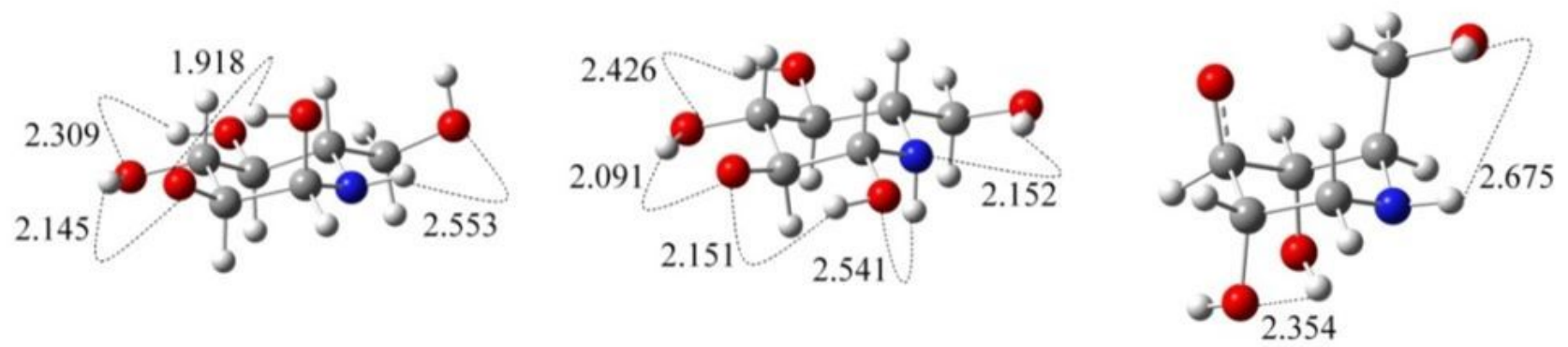

$$
\alpha-1-O H 2
$$

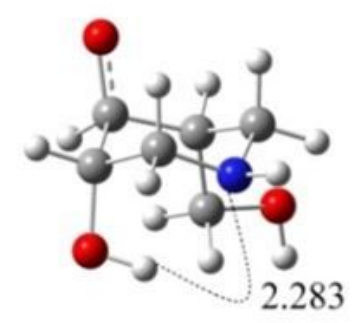

$3-\mathrm{OH} 3$
$\beta-1-O H 2$

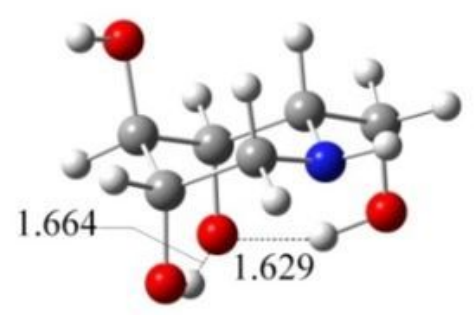

5-OH4
$2-\mathrm{OH} 3$

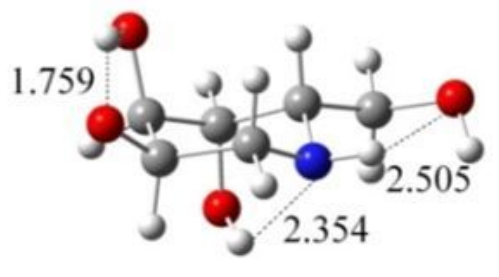

6-OH2

Figure 5

MP2/6-311++G(d,p)//B3LYP/6-311++G(d,p) geometries of the lowest energy structures of deprotonated iminosugars 


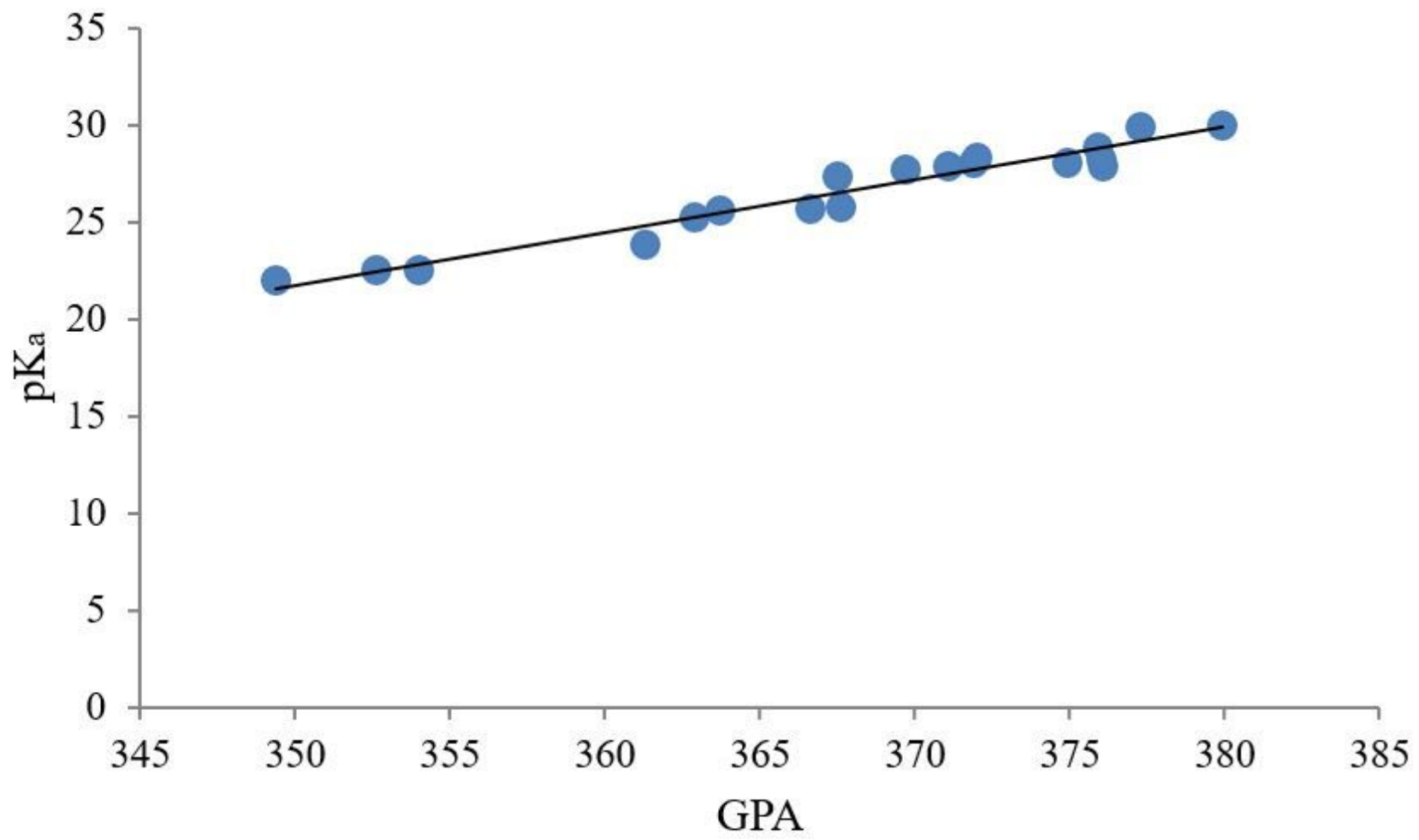

Figure 6

Caculated DMSO pKa values for some polyhydrohylated piperidines versus their computed MP2/6$311++G(d, p) / / B 3 L Y P / 6-311++G(d, p)$ acidities in kcal.mol-1

\section{Supplementary Files}

This is a list of supplementary files associated with this preprint. Click to download.

- Supportinginformation.docx 